\title{
Phase Composition of the Surface Zone of Nitrided Cast Steels and Their Mechanical Properties
}

\author{
K. BRzózKA ${ }^{a, *}$, T.W. BudzynOwski ${ }^{b}$ AND B. GÓRKA ${ }^{a}$ \\ ${ }^{a}$ Department of Physics, Faculty of Mechanical Engineering, Technical University of Radom \\ Krasickiego 54, 26-600 Radom, Poland \\ ${ }^{b}$ Institute of Machines Building, Faculty of Mechanical Engineering, Technical University of Radom \\ Krasickiego 54, 26-600 Radom, Poland
}

\begin{abstract}
Conversion electron Mössbauer spectroscopy and structural X-ray diffractometry have been used to study nitrides formation in the surface layer of cast steels subjected previously to low-temperature nitriding. It has been found that creation of iron-nitrogen phases strongly depends on sample composition. Nitrides: $\gamma^{6}-\mathrm{Fe}_{4} \mathrm{~N}$ and $\varepsilon-\mathrm{Fe}_{2-3} \mathrm{~N}$ arise in the course of the nitriding procedure in most investigated cast steels. Moreover, considerable changes in their microstructure and tribological properties occur. The depth profile of nitrides has been derived for selected cast steel.
\end{abstract}

PACS: 61.66.Dk, 81.65.Lp, 81.40.-z, 76.80.+y, 61.05.cp, 68.37.-d, 81.40.Pq

\section{Introduction}

Chemical and thermal treatment is a common method for improving some mechanical and chemical properties of the host material. Between others, various techniques of nitriding are very useful for profitable modification of mechanical characteristics of steel [1-4]. This is particularly important in case of cast steel, owing to possibility of inexpensive and precise production of metal details of machines and devices. In contrast to steel [4-9], there are not many papers devoted to tribological peculiarities of nitrided cast steel up to now [10-13]. In present paper, an influence of nitriding on phase composition and tribological characteristics of the surface zone of highlyalloyed cast steels has been examined.

\section{Experimental methods}

A set of four highly-alloyed cast steels, denominated: $\mathrm{I}, \ldots, \mathrm{IV}$, was the object of investigations. Real chemical composition of the materials is seen in Table I. The cast steels were subjected to a low-temperature nitriding procedure carried out in the Institute of Precision Mechanics in Warsaw. The processing included two stages: in the first one the cast steel was exposed to four hours long treatment in pure ammonia at $480{ }^{\circ} \mathrm{C}$, while in the second one a mixture of ammonia $(40 \%)$ and previously dissociated ammonia $(60 \%)$ was applied at $530{ }^{\circ} \mathrm{C}$ during 16 hours.

Phase composition of the surface zone has been investigated by means of conversion electron Mössbauer

* corresponding author; e-mail: k.brzozka@pr.radom.pl
TABLE I

Real concentration of alloying constituents (in weight \%) in investigated cast steels. The small amount of phosphorus $(<0.03 \%)$ and sulphur $(<0.015 \%)$ was neglected.

\begin{tabular}{c|c|c|c|c|c|c|c|c|c|c}
\hline \hline Smp. & $\mathrm{C}$ & $\mathrm{P}$ & $\mathrm{S}$ & $\mathrm{Si}$ & $\mathrm{Mn}$ & $\mathrm{Ni}$ & $\mathrm{Cr}$ & $\mathrm{Mo}$ & $\mathrm{V}$ & $\mathrm{Cu}$ \\
\hline I & 0.55 & 0.03 & 0.02 & 0.53 & 0.42 & 0.6 & 13.7 & 0.35 & 0.26 & 1.82 \\
II & 0.18 & 0.014 & 0.007 & 0.54 & 0.42 & 0.65 & 13.7 & 0.76 & 0.24 & 1.58 \\
III & 0.46 & 0.024 & 0.009 & 0.44 & 0.52 & 0.7 & 1.0 & 0.44 & 0.52 & 1.13 \\
IV & 0.38 & 0.028 & 0.006 & 0.45 & 0.44 & 0.77 & 15.0 & 0.48 & 0.21 & 1.80
\end{tabular}

spectroscopy (CEMS) and X-ray diffractometry (XRD), both for as-cast materials and nitrided ones. Mössbauer measurements were performed using ${ }^{57} \mathrm{Co}(\mathrm{Rh})$ source of gamma radiation and a gas-flow CEMS detector supplied with $\mathrm{He}+4 \% \mathrm{CH}_{4}$ mixture. For selected cast steels, analysis of phase composition has been further performed in dependence on depth of the layer under the nitrided surface. CEMS spectra were recorded after sequential rub of several $0.001 \div 0.01 \mathrm{~mm}$ thick layers. In order to resolve Mössbauer spectra, program NORMOS was used. Structural measurements were carried out at room temperature, by means of powder X-ray diffractometer (Broker D8 Discover) using filtered $\mathrm{Cr} \mathrm{K} \alpha$ radiation $(\lambda=0.228970 \mathrm{~nm})$, in the angle range $20^{\circ} \leq 2 \Theta \leq 150^{\circ}$.

Microstructure of the cast steel surface (before and after nitriding) was examined by means of optical microscope. Abrasive wear resistance was investigated using test of friction in system: three rollers-cone, according to the PN-83/H-04302 Polish Standard. Moreover, tracks of wiping were analysed by use of reflecting electron microscope. 


\section{Phase composition}

\subsection{XRD results}

X-ray diffraction studies of the as-cast samples show prevalence of $\alpha$-Fe phase and less or more considerable content of $\gamma$-Fe one. XRD patterns of nitrided samples are presented in Fig. 1, while a set of identified phases is collected in Table II. XRD outcomes show that, after nitriding, $\gamma^{\prime}-\mathrm{Fe}_{4} \mathrm{~N}$ is a predominant phase in sample III and it is also significant in sample II but does not exist in samples I and IV. However, a small amount of $\varepsilon$-nitrides has been found in sample I and, in much smaller extent, in samples IV and III.

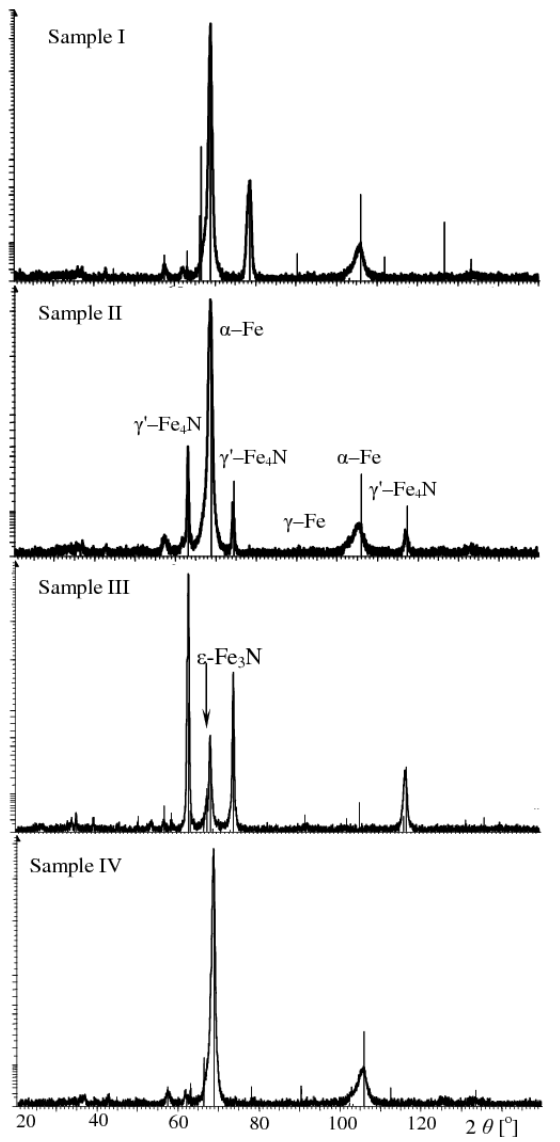

Fig. 1. XRD pattern obtained for nitrided cast steels (with exemplary indicated phases).

\subsection{Surface CEMS investigations}

Mössbauer spectra collected before and after nitriding are presented in Fig. 2. They comprise several discrete components in form of Zeeman sextets and one or two paramagnetic patterns in form of some doublets or singlets. The sextets are attributed to ferrite $(\alpha$-Fe solid solution $-1 \div 3$ sextets) as well as iron nitrides. Besides, much smeared component is present which originates from martensite. It is reproduced by means of sextet with distributed magnetic hyperfine field. The paramagnetic components are identified as austenite $(\gamma$-Fe $)$
TABLE II

Phases identified in investigated cast steels by means of XRD.

\begin{tabular}{c|c|c|c|c|c|c}
\hline \hline \multicolumn{2}{c|}{ Sample } & $\alpha-\mathrm{Fe}$ & $\gamma-\mathrm{Fe}$ & $\gamma^{\prime}-\mathrm{Fe}_{4} \mathrm{~N}$ & $\varepsilon-\mathrm{Fe}_{3} \mathrm{~N}$ & $\varepsilon-\mathrm{Fe}_{2} \mathrm{~N}$ \\
\hline \multirow{2}{*}{$\mathrm{I}$} & as-cast & $\mathrm{x}$ & $\mathrm{x}$ & & & \\
\cline { 2 - 7 } & nitrided & $\mathrm{x}$ & $\mathrm{x}$ & & & $\mathrm{x}$ \\
\hline \multirow{2}{*}{$\mathrm{II}$} & as-cast & $\mathrm{x}$ & & & & \\
\cline { 2 - 7 } & nitrided & $\mathrm{x}$ & & $\mathrm{x}$ & & \\
\hline \multirow{2}{*}{$\mathrm{III}$} & as-cast & $\mathrm{x}$ & $\mathrm{x}$ & & & \\
\cline { 2 - 7 } & nitrided & $\mathrm{x}$ & & $\mathrm{x}$ & $\mathrm{x}$ & \\
\hline \multirow{2}{*}{$\mathrm{IV}$} & as-cast & $\mathrm{x}$ & $\mathrm{x}$ & & & \\
\cline { 2 - 7 } & nitrided & $\mathrm{x}$ & & & & $\mathrm{x}$
\end{tabular}
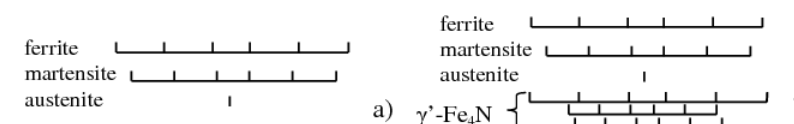

austenite

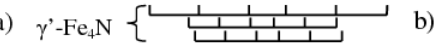
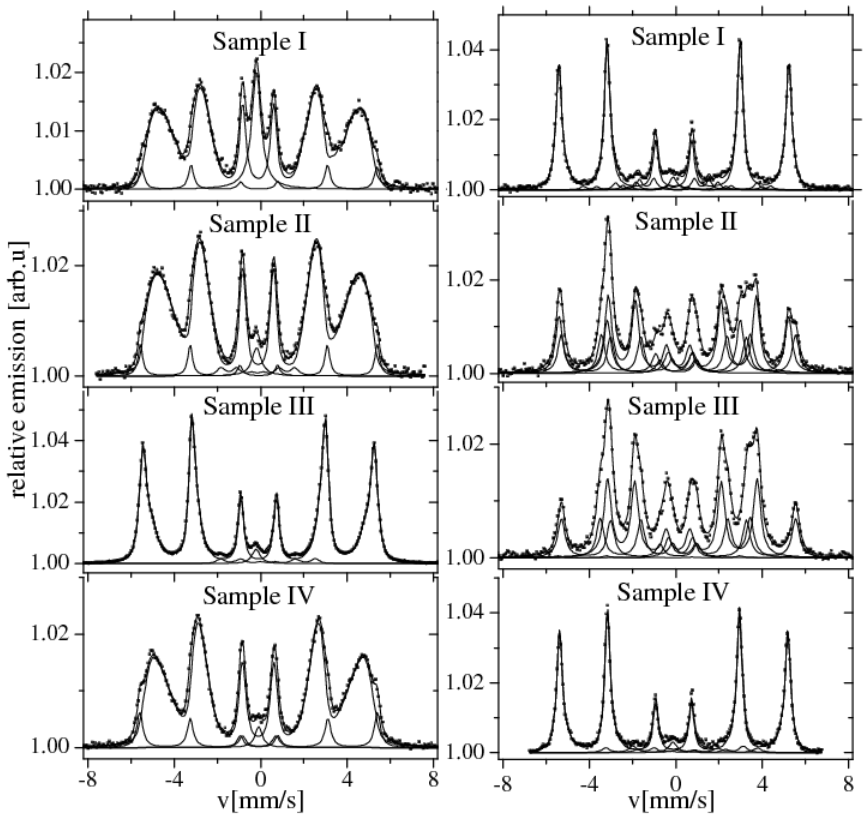

Fig. 2. CEMS spectra of cast steels: (a) as-cast, (b) after nitriding.

and vestigial: nitride austenite, iron carbide or iron oxide.

Owing to complexity of the spectra, special attention has been paid to identification of individual phases, especially iron nitrides. In iron-nitride systems, well-known stable (at room temperature) phases: $\gamma^{6}-\mathrm{Fe}_{4} \mathrm{~N}, \varepsilon-\mathrm{Fe}_{3.2} \mathrm{~N}$, $\varepsilon-\mathrm{Fe}_{3-x} \mathrm{~N}$ and $\varsigma-\mathrm{Fe}_{2} \mathrm{~N}$ have several components of similar hyperfine parameters. Therefore, in order to distinguish the phases credibly, fitting the spectra with some imposed restrictions was realized. The preliminary analysis showed that $\gamma^{6}-\mathrm{Fe}_{4} \mathrm{~N}$ dominates among phases comprising nitrogen in some nitrided samples. As the subspectrum of this phase consists of three sextets with specific 
intensities proportion, the main constraint was a fixed intensities ratio $(1: 2: 1)$ of three sextets composing $\gamma^{6}-\mathrm{Fe}_{4} \mathrm{~N}$ pattern - with magnetic hyperfine field values equal to about: $34 \mathrm{~T}, 21.5 \mathrm{~T}, 21.9 \mathrm{~T}$, isomer shift values (relative to pure iron) equal to: $0.24 \mathrm{~mm} / \mathrm{s}, 0.31 \mathrm{~mm} / \mathrm{s}, 0.30 \mathrm{~mm} / \mathrm{s}$ and quadrupole splitting values: $0 \mathrm{~mm} / \mathrm{s}, 0.19 \mathrm{~mm} / \mathrm{s}$, $-0.39 \mathrm{~mm} / \mathrm{s}$, respectively. Such a fitting procedure allows us to separate also the ferrite component and $\gamma^{6}$ $\mathrm{Fe}_{4} \mathrm{~N}$ ones. The phase composition of individual samples, obtained by numerical analysis of spectra, is presented in Table III. The relative fraction of iron atoms contributed to individual phases was estimated on the base of the area of the spectral lines assuming similar $f$-factor of different subspectra.

TABLE III

Phase composition of investigated cast steels (in \%) derived from Mössbauer spectra.

\begin{tabular}{c|c|c|c|c|c|c|c}
\hline \hline \multicolumn{2}{c|}{ Sample } & $\alpha$-Fe & mart. & $\gamma^{\prime}-\mathrm{Fe}_{4} \mathrm{~N}$ & $\varepsilon-\mathrm{Fe}_{3-x} \mathrm{~N}$ & aust. & others \\
\hline \multirow{2}{*}{ I } & as-cast & 7 & 79 & - & - & 14 & - \\
\cline { 2 - 8 } & nitrided & 81 & - & - & 17 & 2 & - \\
\hline \multirow{2}{*}{ II } & as-cast & 8 & 86 & - & - & 3 & 3 \\
\cline { 2 - 8 } & nitrided & 26 & - & 71 & - & - & 3 \\
\hline \multirow{2}{*}{ III } & as-cast & 95 & - & - & - & 2 & 3 \\
\cline { 2 - 8 } & nitrided & 1 & - & 96 & - & 3 & - \\
\hline \multirow{2}{*}{ IV } & as-cast & 7 & 79 & - & - & 11 & 3 \\
\cline { 2 - 8 } & nitrided & 89 & - & - & 9 & - & 2
\end{tabular}

Significant changes in phase structure of investigated specimens have been found as an effect of nitriding procedure. While components characteristic of ferrite, martensite, and (in much smaller extent) austenite dominate in spectra of the as-cast samples, a significant contribution of patterns attributed to iron nitrides are mainly observed for most cast steels after nitriding. The phase $\gamma^{\prime}-\mathrm{Fe}_{4} \mathrm{~N}$ dominates in nitrided samples II and III - it amounts above $70 \%$. On the contrary, this phase is absent in nitrided samples I and IV, but small amount $\varepsilon$ $\mathrm{Fe}_{3-x} \mathrm{~N}$ is stated instead. Substantial increase of relative ferrite percentage and reduction of martensite content is also observed in all cast steels after nitriding.

The outcomes prove that applied nitriding procedure was not very efficient in cases of samples characterized themselves by maximal content of chromium and, simultaneously, with relatively high carbon concentration, which probably prevents formation of iron nitrides. In other samples, $\gamma^{6}-\mathrm{Fe}_{4} \mathrm{~N}$ predominates in the surface layer, especially in sample III that comprises the smallest percentage of chromium. A small amount of phases $\varepsilon$ is also present, which is probably the effect of oxidation of the perovskite $\gamma^{6}-\mathrm{Fe}_{4} \mathrm{~N}$ phase towards the hexagonal one [14].

The results are qualitatively consistent with the findings of XRD investigations. Although, because of complexity of CEMS spectra, the components originating from $\varepsilon$-nitrides have been not well resolved but the global content of these phases is in good accordance with structural examinations. It is worth noticing that CEMS allows distinction between ferrite and martensite and we can observe transformations of these phases.

\subsection{Depth profile of nitric phases}

In CEMS method, conversion electrons and Auger electrons are detected, that are emitted as a result of deexcitation of Mössbauer nuclei (in our case ${ }^{57} \mathrm{Fe}$ ) through the conversion effect. The thickness of layer, which the electrons come from, equals about $150 \mathrm{~nm}(65 \%$ electrons originate from $60 \mathrm{~nm}, 96 \%$ - from $300 \mathrm{~nm}$ [15]), therefore CEMS yields information about very thin zone at the investigated surface. This allows use of CEMS in order to investigate depth profile of selected feature of a specimen. In our work, examination of iron nitrides percentage as a function of depth under the nitrided surface has been performed for sample III, which appeared the most susceptible for nitriding.

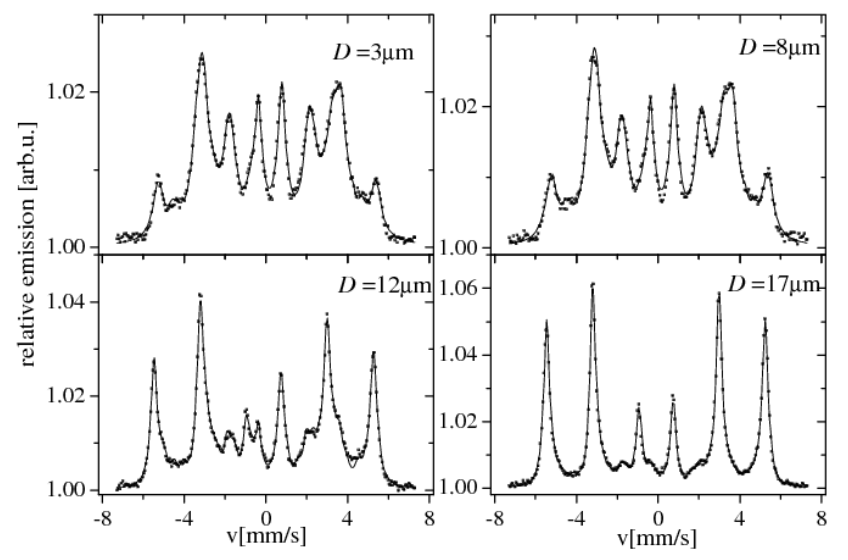

Fig. 3. CEMS spectra of sample III (see Table I) for different depth $D$ of investigated layer under the nitrided surface.

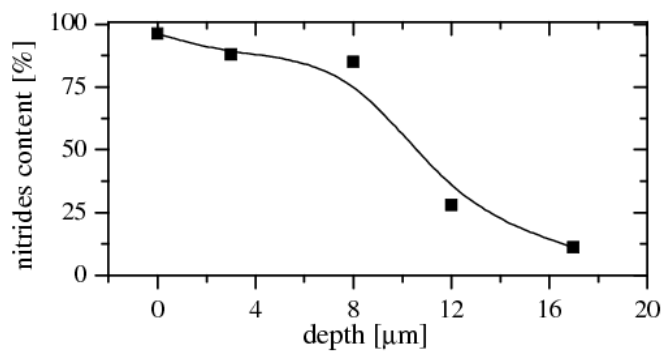

Fig. 4. Depth profile of iron-nitrogon phases derived from CEMS for sample III (see Table I).

CEMS spectra collected after abrasion (by hand) of the thin layer of definite thickness are presented in Fig. 3; the total depth $D$ under the initially nitrided surface is also indicated. The spectra show decreasing percentage of $\gamma^{\prime}-\mathrm{Fe}_{4} \mathrm{~N}$ phase as well as rising content of martensite 
and ferrite. A depth profile of iron nitrides is shown in Fig. 4. As seen, in the surface $8 \mu \mathrm{m}$ thick zone the percentage of nitrides decreases slowly while for deeper layers it is reduced much faster. The effective thickness of the layer of iron-nitrogen phases in investigated sample equals about $12 \mu \mathrm{m}$. It should be noticed that the spectrum collected for $D=17 \mu \mathrm{m}$ is quite similar as the spectrum obtained for the as cast sample. This means that for that composition the structural changes proceeding in the course of nitriding are limited to the surface zone of such a thickness.

\section{Microstructure and mechanical properties}

The influence of nitriding on tribological properties of the cast steels has been examined by carrying out the test of friction in system: three rollers-cone. The results are presented in Fig. 5. Although it has been found that all investigated samples show enlarged abrasive wear resistance after nitriding, the value of this effect is different. The minimal reduction of depth of wiping (close to zero) is observed for sample I, the maximal for samples III and IV. In sample I the improvement of tribological properties is very small, but the abrasive wear resistance is good both before and after nitriding. Time evolution of wear suggests that the effect of betterment is quite durable.

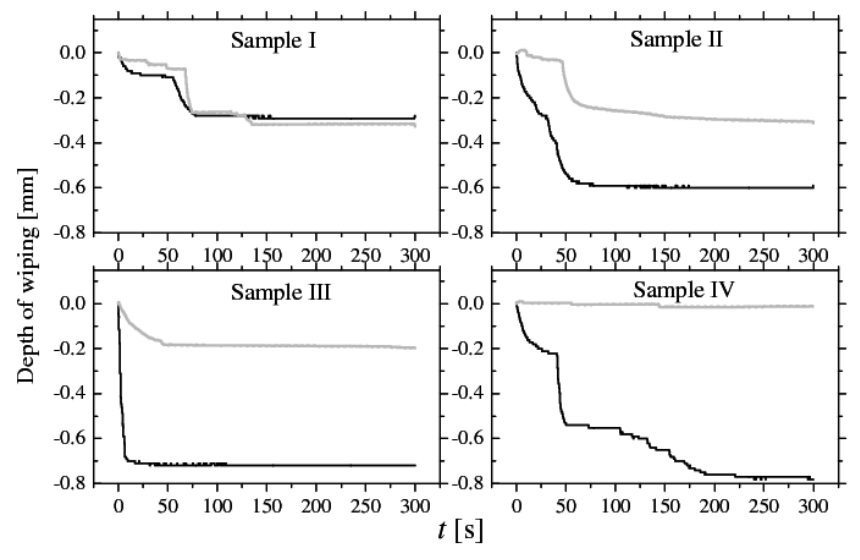

Fig. 5. Results of the test of friction in system: three rollers-cone (according to the PN-83/H-04302 Polish Standard). The black lines and the grey ones are related to the as-cast and nitrided specimens, respectively. a)

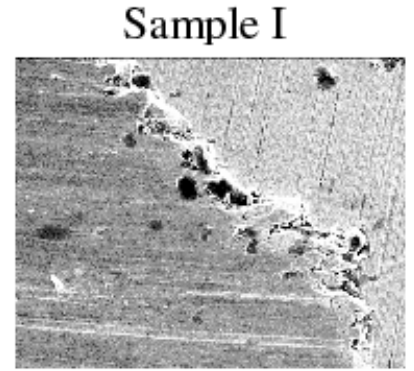

b)

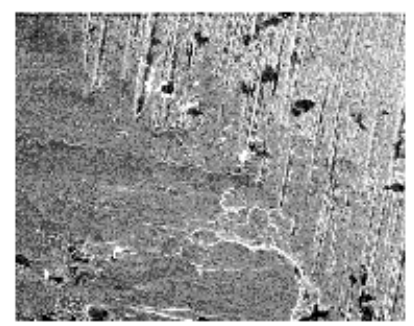

Sample II
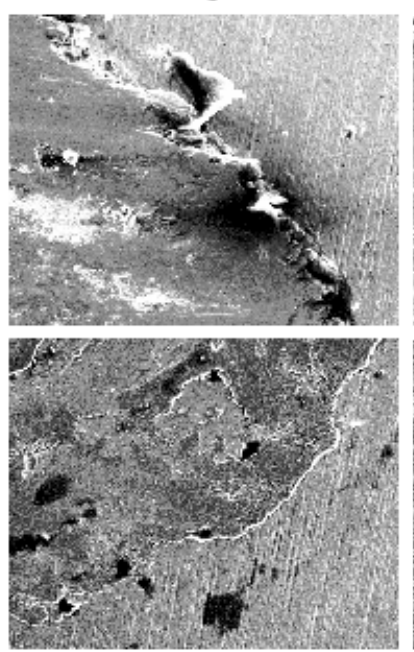

Sample III
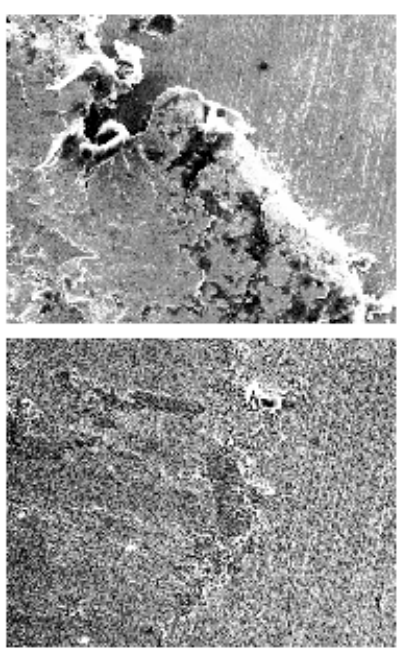

Sample IV
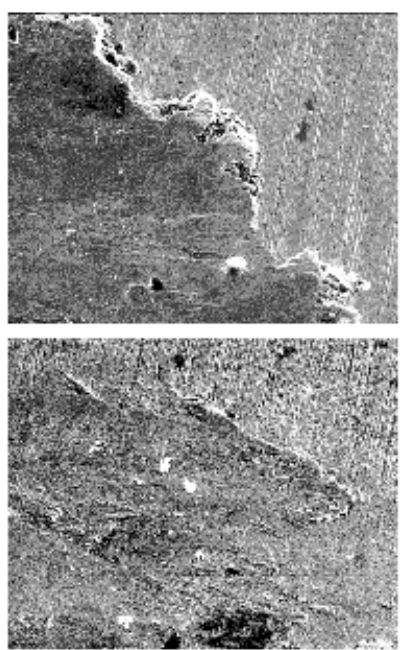

Fig. 6. Tracks of wiping recorded by means of reflecting electron microscope (100x) for: (a) as cast samples; (b) nitrided samples.

Tracks of wiping recorded by means of reflecting electron microscope are shown in Fig. 6. Their analysis proves that the process of attrition of as cast steels of low hardness causes, besides of fine defects, also plastic deformation. In all samples the nitriding procedure induces comminution and unification of surface layer structure, independently on chemical composition of the cast steel. This conclusion is confirmed by results of microstructure investigations performed with optical microscope.

\section{Summary}

Evolution of phase composition and tribological properties of the surface zone of highly-alloyed cast steels subjected to low-temperature nitriding was examined. CEMS and XRD outcomes proved that iron nitrides were formed in all cases apart from the sample comprising maximal amount of chromium. High concentration of chromium together with relatively large content of carbon caused formation of $\varepsilon$-nitrides (Sample I). In other 
cast steels, $\gamma^{6}-\mathrm{Fe}_{4} \mathrm{~N}$ predominated in the surface layer. The effective width of zone comprising iron-nitrogen phases equals about $12 \mu \mathrm{m}$. The substantial reduction of martensite due to nitriding was also stated. The results of tribological as well microscopic measurements evidenced enlarged abrasive wear resistance of the specimens submitted to the nitriding, which is a consequence both of formation of iron nitrides and improvement of microstructural characteristics.

\section{References}

[1] J.R. Davis, Gear Materials, Properties, and Manufacture, ASM International, Materials Park 2005, p. 227.

[2] M.P. Fewella, J.M. Priest, M.J. Baldwin, G.A. Collins, K.T. Short, Surf. Coat. Technol. 131, 284 (2000).

[3] J.-D. Kamminga, G.C.A.M. Janssen, Surf. Coat. Technol. 200, 5896 (2006)

[4] J. Tarcikowski, J. Senatorski, W. Panasiuk, Met. Sci. Heat Treat. 37, 48 (1995).

[5] G. Nicoletto, A. Tucci, L. Esposito, Wear 197, 38 (1996).

[6] P. Kochmański, J. Nowacki, Surf. Coat. Technol. 200, 6558 (2006).
[7] J.F. Lin, K.W. Chen, C.C. Wei, C.-F. Ai, Surf. Coat. Technol. 197, 28 (2005).

[8] J. Piekoszewski, L. Waliś, J. Langner, Z. Werner, J. Białoskórski, L. Nowicki, M. Kopcewicz, A. Grabias, Nucl. Instrum. Methods Phys. Res., Sect. B 114, 263 (1996).

[9] P. Budzyński, P. Tarkowski, E. Jartych, A.P. Kobzev, Vacuum 63, 737 (2001).

[10] X. Nie, L. Wang, Z.C. Yao, L. Zhang, F. Cheng, Surf. Coat. Technol. 200, 1745 (2005).

[11] A. Kabała-Trzaskowska, T.W. Budzynowski, Inz. Mat. 147, 403 (2005).

[12] V.N. Starostin, E.I. Pytyaeva, V.V. Pershina, Met. Sci. Heat Treat. 40, 421 (2006).

[13] K. Brzózka, T.W. Budzynowki, B. Górka, M. Gawroński, J. Phys. Conf. Ser. 217, 012070 (2010).

[14] V.K. Garg, A.C. Oliveira, R.B. Azevedo, M. Wagener, N. Buske, P.C. Morais, J. Magn. Magn. Mater. 272, 2326 (2004).

[15] K. Nomura, in: Mössbauer Spectroscopy in Materials Science, Eds. M. Miglierini, D. Petridis, Kluwer Academic, 66, 63 (1998). 